\title{
Empirical Study on the Improvement of the Level of German Football Competition in the Youth Training System
}

\author{
Huang Guangliang ${ }^{1}$ \\ ${ }^{1}$ Guangxi College of Sports and Physical Education, Nanning, Guangxi 530012
}

Keywords: youth training; German football

\begin{abstract}
The German football teams won two U21 European Youth Championships and Confederations Cup gold medals in just three days. In particular, these two teams are dominated by new generation players, which makes the focus of the circle once again gathered in the German football. German football talents continue to emerge as blowouts, making other countries envy. This paper elaborates on the four aspects of the construction of German youth training, the input of youth training, the number of coaches, and the size of domestic registered players. It can be clearly seen that the fruitful results achieved by German football are not overnight. Therefore, it is necessary to focus on the specific implementation of youth training to promote the development of football.
\end{abstract}

\section{Introduction}

At the end of the last century and the beginning of this century, German football also suffered from untold suffering. Despite winning the championship in the European Cup in 1996, they encountered Waterloo in the 1998 FIFA World Cup. With a shocking score of 0:3, they were eliminated by the big black horse of Croatia at the time. The entire losing process triggered a shock to the domestic football. Since then, in the 2000 European Cup group stage was eliminated early, especially in the last 0:3 loss to Portugal, which has dispatched a large number of substitutes. German football is once again humiliated. At the time, Mateus, who was nearly 40 years old, still played the main part of the national team, but the team's 25-year-old player was only Barak and Deisler. Although he won the World Cup runner-up at the 2002 World Cup, it was only a flash in the pan [1].

In this regard, the German Football Association has deeply realized that domestic football needs a re-transformation. In addition to maintaining the original style of tenacious will and strong body, they also need to inject new technologies and tactics into their own football. The live factor of football trend. In order to find the best way and method to develop and improve the country's football again, the German Football Association did not hesitate to send out a large number of study tours. In the end, the German football reform focused on the training of young football.

\section{Research Content}

Football is picked up from the dolls. In contrast, this rigorous Germanic people perform more thoroughly. For the implementation of youth training has always been comprehensive, there are clear and detailed training plan, there are strict requirements of various stages, and there are strict supervision system to ensure the implementation of the club, so that all players trained are comprehensive, directly meet the various different needs of clubs and national teams.

\section{The Construction of the Youth Training in Germany and the Policy}

(1) Based on each professional football club, establish a professional system for youth clubs in youth training. According to the requirements of the German Football League, the construction of youth training has been incorporated into the hard indicators of each club to participate in the professional league qualification review. Every Bundesliga and Bund Club must have a youth training center that meets professional standards, or they will be disqualified from participating in 
the league. For example, each Bundesliga youth level must have 3 professional venues and 3 professional coaches [1]. In addition, the German Football League has also formulated very strict specific standards for many details related to youth training, such as goalkeeper coaching, team medical conditions and nutrition counseling. For each club, these hard indicators must be followed, otherwise they will be "one vote veto." Through the cooperation between the German Football Association and the German Football League, 366 youth training bases have been established nationwide. Among them, there are about 14,000 young players with good prospects aged 11-14[2]. The base also has a sufficient number of professional coaches. The base is responsible for the careful guidance of the young players, and is equipped with a full range of professional venues and equipment, which has laid a solid foundation for the further development of German football.

(2) Perseverely adhere to the "50+1" policy. This policy can be said to be the biggest reliance on the reform of the Football Association. Specifically, the decision-making power of the club can only be owned by the club. Even if the private or company owns more than $50 \%$ of the ownership, it cannot really control the club. Under this policy, the highest power of German clubs is at least superficially a fan, and their development and decision-making need not be completely constrained by the personal preferences behind the capital. In order to serve the club's fans, the development of community football, especially youth football, has become an unshirkable responsibility of the teams.

It is with a series of bold and targeted reforms, and consistent and effective policies that German football can once again rise rapidly from the bottom. As in recent years, they have always been able to leave a glimpse of power in the world football: 2010 4:0 Australia, 4:1 England, 4:0 Argentina; 2014 4:0 Portugal, 7:1 Brazil; and frequent Winning to victory: 2006 World Cup runner-up, 2008 European Cup and runner-up, 2010 World Cup runner-up, 2012 European Cup semi-finals, 2014 World Cup championship and 2016 European Cup semi-finals... German football is accumulating with youth A footprint will eventually complete the Phoenix Nirvana and return to the pinnacle of international football[2].

\section{To Increase Investment in Youth Training all over the Country}

If we say that German football will focus on the training of youth training, then whether or not supporting funds can be put in place is the key to the success of the reform. In this regard, the Germans once again demonstrated their strong execution. From the German Football Association, the German Football League, down to the clubs, they all obeyed and implemented without hesitation. Even if the Kirch Group bankruptcy in the early 2000s brought a huge economic blow, the clubs would rather tighten their belts in the transfer market and ensure that they will invest in the development of youth training each year [3]. At the beginning, German football's investment in youth training is approximately 48 million euros per year. As German football advances, the Bundesliga and Germany B leagues flourish, and investment in youth training has also increased year by year. According to incomplete statistics, in the past ten years, the expenses of the German Football Association and clubs in the development of youth training have exceeded 96 million euros each year, close to 100 million. This does not include social forces and personal investment. At present, the German Football Association has established 52 youth training centers and 366 regional youth training centers, almost every corner of the country.

Take the example of the youth training center just completed by the Bundesliga leader Bayern Munich. In retrospect, young players were once an important part of Bayern's first team. However, after Albaba in 2010, Bayern Youth Training did not provide any more backbone strength to the first team. In 2015, after returning to his post, the club's president, Hennesse, first devoted herself to the club's youth training work and focused on promoting the construction of a new youth training center with a cost of over 70 million euros [3]. Today, the new youth training center with actual expenditure of 100 million euros has been completed, and Bayern has also chosen the former team assistant Gullland, who has rich experience in youth training, as the head of the youth training center. Undoubtedly, this is the highest level of youth training facilities in Europe at the moment. It will surely be a star dream factory in Bayern Munich and even the entire German football. Former 
Bayern coach Guardiola also praised this youth training center as the best plan for German football and Bayern club. Many new Lam, Muller or Schweins will emerge here in the future. Tiger, this is a more cost-effective investment than buying two super stars.

\section{A Large Team of Coaches}

In the youth's football enlightenment phase, whether or not a good coach can be encountered and he can accept his guidance and help plays a crucial role in his entire career. Although the physical qualities and indomitable will of the German youth are inherent, the best Chollima needs the guidance and carving of Bole. Faced with the heavy task of developing youth football, the strict Germans certainly do not ignore this simple truth. As a result, the German Football Association gave priority to the cultivation of young coaches in the process of promoting young players.

The German Football Association first tried to reduce the threshold for training football coaches and introduced the most inexpensive course of education in Europe. For example, only $£ 340$ was required for UEFA B-level coaching courses, which in England required $£ 750$ to $£ 2,550$, which made Germany Soon there will be a huge team of coaches who can laugh and admire football, at least to ensure that the coach's optional base is large enough. According to UEFA statistics, Germany has more than 28,000 coaches with a B-level certificate, the UK has more than 1,700 coaches with a B-level certificate, more than 5,500 A-level certificate coaches, and the UK has more than 900 coaches holding an A-level certificate) and There are more than 1,000 Pro-level certificate coaches and more than 100 British Pro-level certificate coaches. It can be seen that the number of German coaches is 10 times that of Britain and the cost of learning is only a fraction of that of the United Kingdom. The vast majority of them now focus on youth training, providing the most crucial mentoring foundation for German football training for future pillars [4].

In addition, even if it is a qualified coach, the German Football Association will regularly arrange training and do one-on-one instruction as much as possible. There is no lack of big players in these coaches, especially the youth training coaches. For example, in the German team of the 2006 World Cup, Borowski, Neuville, Asamoah and others are currently serving as youth coaches in their respective clubs. In the history of Germany, Asamoah, the first black international player, has excitedly stated that he has been eager to pass on everything he has to the next generation of players after getting a coach's license, and hopes that they can surpass him sooner. With the help of the words and deeds of idols, the effect of youth training naturally becomes more pronounced.

\section{The Large Number of Domestic Registered Players}

In 2002, the German Football Association officially launched the "Development Plan for Young Players." This program aims to fully tap and cultivate high-quality football talent across the country. According to Daniel, the former chairman of the German Football Association, "Even if a century football genius happens to be born in a small mountain village, we will find him from now on. Train him.” The rigorous style and good execution of the Germans ensured the successful implementation of this plan, and more and more German teenagers actively participated in football. According to statistics, the country already has more than 6.3 million registered players. In other words, one out of every 13 people in Germany is a registered player, and the popularity of football in Germany is amazing to the world. Among the more than 6.3 million registered players, there are about 1.8 million young players, which account for a considerable proportion, and provide a firm talent base for the youth training of German football. German football experts have conducted data analysis on the finished product rate of domestic registered players and pointed out that among the 300,000 professionally trained children, about 10,000 will stand out and become professional players. In this regard, the German football youth training system began to consciously focus on observing and following up on the development of talented players, thus tapping and cultivating the most promising outstanding players for German football [5].

In recent years, the German Football Association has screened more than 20,000 outstanding players aged 11-17 (including women's football) from 366 training bases each year for key training, 
and arranged more than 1,000 professional coaches to conduct one-on-one professional guidance for them. These coaches will even develop a complete set of scientific training programs for each player. This is an important part of the "development program for young players to expand." At the same time, the German Football Association has not relaxed its popularization and promotion of football in addition to the "top students". At present, there are more than 80,000 football teams from 7-15 years old in Germany, more than 18,000 male teams aged 16-19, and more than 6,000 female teams. There are more than 60,000 adult men's teams and over 4,000 adult women's teams. These figures are huge and enviable. Of course, considering the past few players like Klose, Bierhoff, etc., who are innumerable players. In addition to training key players, the German Football Association will never lose sight of the development of any registered player. Therefore, the data system of German football has always been in a state of high rhythm filling in recent years. In this data system, basic information and even recent performance of each player (especially young players) can be queried. This can not only effectively curb falsified behaviors such as changing the age, changing files, etc., but also provide scouts for all clubs [5].

Xinhua News Agency once published an article on "China's 1.3 billion registered players, only 30,000, and Germany's 6 million Pakistani law 1.5 million" during the 2014 World Cup. According to the economists of international accounting and consulting companies, they analyzed a large amount of data and reached a conclusion: The number of players and their interest in football are the key factors for success in the World Cup [5]. Among them, the number of registered players has an effect on the performance of the World Cup accounting for more than 50\%. This means that it is no coincidence that the German team can finally win the Brazilian World Cup because they had more than 6 million registered players at the time, ranking first in the world, and their total population was only 80 million. The number of registered players in Brazil, England, Italy, and France is only around 1.5 million. According to the figures provided by the Chinese Football Association, in 2004 China's registered players were 40,000 in their early years, and in 2009 they were less than 20,000 and in 2013 they were a little over 30,000. If economists come to the conclusion, it is not surprising that the Chinese team often missed the World Cup. As for how to improve the level of Chinese football, and even have a breakthrough in the World Cup? The first step is to start with the number and quality of registered players.

\section{Conclusion}

German football has finally ushered in its own football grandeur with its scientifically rigorous youth training policy and comprehensive economic investment. Of course, such a grand occasion is not an overnight event. It also requires the German Football Association, the German Football League, and even the German clubs and training bases to work together for ten or twenty years. The current German football is in the era of talent blowout. It is no exaggeration to say that the German Football Association can even send two or even three world-class teams to deal with many events at the same time.

From the successful case of German football, it can be found that they can guide the clubs to the development of youth training from the root. German football has never been the so-called U23 policy under the New Deal of the Super League, and it has not created hard opportunities for young players through administrative intervention. However, every club has always spared no effort in the development of youth training. This has only made Germany's football attract world attention. It is worth mentioning that the German team that won the Confederations Cup has an average age of 25 years and 225 days. Even the coach Loew said humbly that "Acquiring the Confederations Cup proves that the German team is still the best team in the world and it is such a young champion team."

Despite holding a series of championships such as the World Cup, Confederations Cup and the European Youth Championship, the German Football Association did not intend to stop here. In today's utilitarian environment, grasping the youth training is actually a matter of "less thankfulness.” This requires patience and persistence. At the beginning of this century, German football has undergone a bold transformation. It is not only willing to spend huge sums of money to 
promote the construction of youth training facilities, but also to take the coaching team as the basis for training talents, and then to take the lead in the world of football in terms of player excavation and training. More importantly, in this series of reform projects, the Germans always adhere to strict style, firm conviction, and strict execution, and finally they have harvested the fruits of today. The young talents of the German football team are almost madly emerging. It is the generational force that has become the goal of European football and even the world of football.

\section{References}

[1] Lian Jianming. Germany's youth training as a hard indicator of the qualifications policies to benefit grassroots [N]. Xinmin Evening News, 2017-06-16

[2] Liu Jia. Germany's youth training investment is approaching 100 million Euros per year. Training bases are spread all over the country. [N]. Southern Morning Post, 2017-07-25

[3] Players: over 6 million. There is 1 player in 13 players. German registered players over 6 million. There are 1 player in 13 players. [EB/OL]. Sohu Sports 2017-08-26

[4] Zhang Jinliang. Special comment: The German spirit is not overnight. Youth training must be eliminated. [EB/OL]. Sohu Sports 2017-10-22

[5] Zhaohui. Big data! Why is it so successful to analyze the German youth training? [EB/OL]. Sohu Sports 2017-10-22 